\title{
Bridging the gap between basic science and clinical curricula: lessons from SARS-COV-2 pandemic
}

\author{
Katia Cortese ${ }^{1}$ (D) $\cdot$ Marco Frascio $^{2,3}$ (D)
}

Received: 12 April 2021 / Accepted: 16 April 2021 / Published online: 24 April 2021

(c) The Author(s), under exclusive licence to Springer-Verlag France SAS, part of Springer Nature 2021

\section{Dear Editor,}

We read with great interest the inspiring collection of papers Education in Anatomy (Volume 43, issue 4, April 2021), and we wish to share our scientific view on this topic.

Everybody knows that severe acute respiratory syndrome coronavirus-2 (SARS-CoV-2) has spread to become a global pandemic. From studies on Neanderthal's gene clusters associated with severe COVID-19 [5], to vaccine and therapeutics development, histopathological examination of patient's tissues, and structural basis of virus protein's antigenicity, the worldwide research community is spending tremendous efforts in understanding COVID-19 disease. Can we exploit all this knowledge to make anatomy more relevant for the future? From the educational perspective, although e-learning strategies for medical education were already developed, COVID-19 pandemic has generated a global need for new communication technologies [3]. However, the acquisition of hands-on experience from dissection courses is still very appreciated by students. To date, the shut-down of those courses and of body donation programs for safety concerns generated great difficulties to restart dissection practice in many countries. Whatever the teaching method will be in the post-COVID-19 future, face-to-face, online or blended, the pandemic is an opportunity for anatomy educators to stay up-to-date and to boost new connections between anatomy and clinical curricula. Indeed, COVID-19 raised some

Katia Cortese

cortesek@unige.it

1 Cellular Electron Microscopy Laboratory, DIMES, Department of Experimental Medicine, Human Anatomy, School of Medical and Pharmacological Sciences, University of Genoa, Via Antonio de Toni 14, 16132 Genoa, Italy

2 Department of Surgical Sciences and Integrated Diagnostics, School of Medical and Pharmacological Sciences, University of Genoa, Genoa, Italy

3 General Surgery Unit, IRCCS Policlinic San Martino Hospital, Genoa, Italy considerations on which subjects really matter for trainees [2]. From the basic science perspective, the last 20 years have seen impressive advances in microscopic imaging techniques. Cryo-electron microscopy and 3D tomography have resolved SARS-COV-2 architecture and Spike protein antigenicity, while transmission electron microscopy (TEM) on ultrathin sections of isolated virus particles revealed virus morphological features, like size of peplomers and nucleocapsid, providing a suitable reference for research on more complex tissues. However, EM on patients' tissues is considered a very challenging task and a consistent number of publications show the presence of putative SARS-CoV-2 virus by electron microscopy (EM) in tissues are actually showing coated vesicles, multivesicular bodies, and crosssectioned endoplasmic reticulum [1]. Why is this happening? The reasons originated from the progressive decline of the time dedicated to anatomy teaching and basic science coupled with the fact that EM facilities requires specialized scientists and very expensive instrumentation. These factors determined an irreversible loss of expertise so dramatically evident in the current scientific literature [4]. From the educational viewpoint, the integration within a lecture on the respiratory system for medical students of topical ultrastructural images derived from COVID-19 human lungs obtained in our university during the first wave of pandemic coupled with lungs CT-scan of the same patients, immediately raised the attention of scholars.

In conclusion, more than 1 year of remote teaching in the pandemic has, in our opinion, definitively changed the perception of the role of anatomy, teaching methods, and subjects that really matter in clinical curricula. In our vision of the post-pandemic future, we think that blended learning including online didactic lectures, virtual dissections, medical imaging, and simulated-surgery training associated with a face-to-face problem-based learning and/or research-based strategies will certainly be an innovative element for medical and health professions education. 


\section{References}

1. Bullock HA, Goldsmith CS, Zaki SR et al (2021) Difficulties in differentiating coronaviruses from subcellular structures in human tissues by electron microscopy. Emerg Infect Dis 27:1023-1031. https://doi.org/10.3201/eid2704.204337

2. Evans DJR, Pawlina W (2021) Effects of COVID-19: the need to assess the real value of anatomy education. Anat Sci Educ 14:129-131. https://doi.org/10.1002/ase.2061

3. Frascio M, Gervasoni M, Lazzara F, Mandolfino F, Noceti M, Sguanci M, Vercelli G (2009) New teaching models for the medical school of medicine: Comparison between oral an online classes. The experience of the Genoa school of medicine. J E-Learn Know Soc 5(3):43-48
4. Singh R, Shane Tubbs R, Gupta K et al (2015) Is the decline of human anatomy hazardous to medical education/profession?-A review. Surg Radiol Anat 37:1257-1265. https://doi.org/10.1007/ s00276-015-1507-7

5. Zeberg H, Pääbo S (2020) The major genetic risk factor for severe COVID-19 is inherited from Neanderthals. Nature 587:610. https://doi.org/10.1038/s41586-020-2818-3

Publisher's Note Springer Nature remains neutral with regard to jurisdictional claims in published maps and institutional affiliations. 